\title{
Single Cell Flow Cytometry Assay for Peptide Uptake by Bacteria \\ Monica Benincasa ${ }^{1, \#}$, Quentin Barrière ${ }^{2, \#}$, Giulia Runti ${ }^{1}$, Olivier Pierre ${ }^{2}$, Mick Bourge ${ }^{2}$, Marco Scocchi ${ }^{1, *}$ and Peter Mergaert ${ }^{2, *}$
}

\author{
${ }^{1}$ Department of Life Sciences, University of Trieste, Trieste, Italy; ${ }^{2}$ Institute for Integrative Biology of the \\ Cell (I2BC), CEA, CNRS, University Paris-Sud, Université Paris-Saclay, Gif-sur-Yvette cedex, France \\ *For correspondence: peter.mergaert@i2bc.paris-saclay.fr; mscocchi@units.it \\ \#Contributed equally to this work
}

[Abstract] Antimicrobial peptides (AMPs) can target the bacterial envelope or alternatively have intracellular targets. The latter requires uptake of the peptide by the bacterial cells. The bacterial internalization of an AMP can be evaluated by a fluorescence-based method that couples the use of the fluorescently labelled AMP to the fluorescence quencher trypan blue. Trypan blue is excluded from the interior of intact cells and the fluorescence of the extracellular peptide or of the peptide bound on the bacterial surface can be quenched by it, while the fluorescence of the internalized peptide is not affected. The uptake of the peptide by the bacteria is determined by measuring the fluorescence in individual cells by flow cytometry.

Keywords: Antimicrobial peptide, Flow cytometry, Peptide uptake, Peptide transporter, Trypan blue, Propidium iodide uptake

[Background] AMPs consist of a broad and diverse class of potent antimicrobials that have potential as novel therapeutic agents (Wang et al., 2015). AMPs are part of innate immunity and are produced by organisms of all kingdoms. They are mobilized by these organisms to fight infecting microbes, that can be either bacteria, fungi or viruses. They do so by directly killing the microbes, but they can also act as sentinels that alert other immune pathways. Interestingly, it has also become clear that AMPs are not only agents against bad microbes, but that they also have key roles in the control of symbiotic bacterial populations in animal and plant hosts (Maróti et al., 2011; Kondorosi et al., 2013).

The diversity of AMPs in sequence and structure is so large that it is difficult to classify them. Moreover, AMPs of different origin have also highly diverse modes of action. They can be broadly divided in peptides that target the bacterial envelope, destroying its cell barrier function by permeabilizing cell membranes, and peptides that are internalized and target a vital intracellular function (Scocchi et al., 2016). Therefore, in the initial characterization of a novel antibacterial peptide, it is important to determine its major site of action. The protocol we described here is based on a flow cytometry method and enables a rapid determination if an AMP of interest is internalized by bacteria at sublethal concentrations (Benincasa et al., 2009). This characterization can be done prior to the biochemical identification of the cellular targets.

We have applied the method to Escherichia coli, Salmonella typhimurium, Sinorhizbobium meliloti and Bradyrhizobium spp. using different antibacterial peptides, including the mammalian Bac7 peptide Copyright $\odot 2016$ The Authors; exclusive licensee Bio-protocol LLC. 
which inhibits the ribosomes (Mardirossian et al., 2014), and the plant peptide NCR247 which permeabilizes bacterial membranes but can also be internalized and bind diverse intracellular targets (Farkas et al., 2014; Guefrachi et al., 2015). This simple method can be easily adapted for use in other bacteria and other AMPs or other types of bioactive peptides. The method is also suitable for testing the activity of peptide uptake transporters in bacteria as illustrated in an example (Mattiuzzo et al., 2007; Guefrachi et al., 2015).

\section{Materials and reagents}

1. Eppendorf tubes

2. Sterile membrane filters $0.2 \mu \mathrm{m}$ (SARSTEDT, catalog number: 83.1826.001)

3. Microscopy slides and cover-glasses (Chance Propper LTD)

4. 96-well microplates, black with transparent bottom, $400 \mu \mathrm{l}$ (Greiner Bio One, catalog number: 655096)

5. Bacteria of interest: e.g., Escherichia coli HB101, BW25113 (Mattiuzzo et al. 2007; Benincasa et al., 2009; Runti et al., 2013; Guida et al., 2015), Salmonella typhimurium ATCC 14028 (Benincasa et al., 2015), Sinorhizobium meliloti Sm1021 (Arnold et al., 2013; Guefrachi et al., 2015), Bradyrhizobium sp. ORS285 (Guefrachi et al., 2015)

6. Bacterial growth media:

a. Mueller-Hinton broth, MHB (see Recipes) (BD, Difco ${ }^{\top M}$, catalog number: 275710), for E. coli or S. typhimurium

b. Yeast extract broth, YEB (see Recipes), for S. meliloti

c. Yeast extract mannitol broth, YMB (see Recipes), for Bradyrhizobium

7. Chemicals and components for bacterial growth media preparation and buffer solutions:
a. Technical agar (BD, Difco ${ }^{\mathrm{TM}}$, catalog number: 281230)
b. Yeast extract (BD, Bacto ${ }^{\mathrm{TM}}$, catalog number: 212750)
c. Peptone (BD, Bacto ${ }^{\top M}$, catalog number: 211677$)$
d. Beef extract (Conda, catalog number: 1700)
e. Saccharose (VWR, catalog number: 27483.363)
f. Mannitol (VWR, catalog number: 25311.297)
g. Sodium glutamate (VWR, catalog number: 27872.298)
h. Magnesium sulfate heptahydrate $\left(\mathrm{MgSO}_{4} \cdot 7 \mathrm{H}_{2} \mathrm{O}\right)(\mathrm{EMD}$ Millipore, catalog number: 105886$)$
i. Dibasic potassium phosphate $\left(\mathrm{K}_{2} \mathrm{HPO}_{4}\right)(\mathrm{VWR}$, catalog number: 26930.362$)$
j. Sodium phosphate dibasic heptahydrate $\left(\mathrm{Na}_{2} \mathrm{HPO}_{4} \cdot 7 \mathrm{H}_{2} \mathrm{O}\right)$ (Sigma-Aldrich, catalog number: S9390)
k. Sodium phosphate monobasic dehydrate $\left(\mathrm{NaH}_{2} \mathrm{PO}_{4} \cdot 2 \mathrm{H}_{2} \mathrm{O}\right)$ (Sigma-Aldrich, catalog number: 71505)
I. Iron(III) chloride $\left(\mathrm{FeCl}_{3}\right)$ (Sigma-Aldrich, catalog number: 701122)
m. Calcium chloride dihydrate $\left(\mathrm{CaCl}_{2} \cdot 2 \mathrm{H}_{2} \mathrm{O}\right)$ (EMD Millipore, catalog number: 102382) 
n. Sodium chloride (NaCl) (EMD Millipore, catalog number: 106404)

o. Sodium hydroxide ( $\mathrm{NaOH})(\mathrm{VWR}$, catalog number: 567530-250)

p. $\mathrm{HCl}$ (CARLO ERBA Reagents, catalog number: 403871)

q. Magnesium chloride $\left(\mathrm{MgCl}_{2}\right)$ (Sigma-Aldrich, catalog number: M8266)

r. Tween 20 (Sigma-Aldrich, catalog number: P1379)

8. Stock solution of fluorescently labelled peptides

Note: Fluorophores successfully used to label peptides are BODIPY FL (Guida et al., 2015), fluorescein (FITC) (Guefrachi et al., 2015), Alexa dye (Benincasa et al., 2010). Before internalization studies, check that labelling does not affect the biological activity of the peptide using a Minimal Inhibitory Concentration assay. Labelled peptides can be synthesized in house if a peptide synthesizer is available or obtained from a commercial supplier offering a custom peptide synthesis service (http://www.proteogenix.science/custom-peptide-synthesis/).

9. Buffered-saline (BS) (see Recipes)

10. Buffered high salt solution (BHSS) (see Recipes)

11. Phosphate buffer (PB) (see Recipes)

12. PB supplemented with Tween 20 (PBT) (see Recipes)

13. Trypan blue (Sigma-Aldrich, catalog number: T6146) stock solution (see Recipes)

14. Propidium iodide (PI) (Sigma-Aldrich, catalog number: P4170) stock solution (see Recipes)

\section{Equipment}

1. Incubator for bacterial growth (FIRLABO, Bioconcept)

2. Thermostatic bath (Thermo Fisher Scientific, Thermo Scientific ${ }^{\mathrm{TM}}$, model: TSGP02)

3. Flow cytometer (Beckman Coulter, model: Cytomics FC 500 equipped with an argon laser [488 $\mathrm{nm}, 5 \mathrm{~mW}$ ) or Moflo Astrios (Beckman-Coulter, model: Moflo Astrios) equipped with an argon laser (488 nm, $100 \mathrm{~mW}$ ) and photomultiplier tube fluorescence detectors for filtered light set at $525 \mathrm{~nm}$ for BODIPY (BY) detection (filter $526 / 52 \mathrm{~nm}$ )

Note: The product 'Cytomics FC 500' has been discontinued.

4. Heraeus ${ }^{\mathrm{TM}}$ Pico $^{\mathrm{TM}}$ and Fresco ${ }^{\mathrm{TM}}$ centrifuge for Eppendorf tubes (Thermo Fisher Scientific, Thermo Scientific ${ }^{\mathrm{TM}}$, model: Heraeus Pico 17)

5. Spectrophotometer (Amersham Biosciences, Ultrospec 10 cell density meter)

6. Confocal microscope with an oil immersion objective lens (Nikon Eclipse C1si or Leica TCS SP $\mathrm{X})$

7. Fluorescence plate reader (Tecan Trading, Infinite ${ }^{\circledR}$, model: M200)

\section{Software}

1. FCS Express 3 or later version (De Novo Software, Los Angeles, CA)

2. Summit 6.2.2 (Beckman-Coulter, Inc.) 
3. Leica Application Suite $X$

4. EZ-C1 Free Viewer (Nikon Corporation)

5. ImageJ (Wayne Resband, National Institutes of Health, USA)

6. Magellan ${ }^{\mathrm{TM}}$ - Data Analysis Software (Tecan Trading AG)

\section{Procedure}

A. Flow cytometry analysis

This procedure uses flow cytometry to determine whether a fluorescently labelled peptide can be internalized by a bacterium of interest. Flow cytometry measures a large number of individual cells and therefore provides a strong support for the significance of peptide uptake.

1. Pick up a single colony of the bacterial strains grown onto agar plates with the appropriate medium.

2. Suspend the bacteria in $5 \mathrm{ml}$ of sterile liquid medium in polypropylene tubes with ventilation cap and incubate with shaking (140 rpm) at $37^{\circ} \mathrm{C}$ for E. coli and S. typhimurium, or $30^{\circ} \mathrm{C}$ for $\mathrm{S}$. meliloti and Bradyrhizobium. Growth is overnight (approximately $18 \mathrm{~h}$ ) for E. coli, S. typhimurium and S. meliloti, and 3 days for the slow growing Bradyrhizobium.

3. Dilute the pre-cultures $1: 30$ in fresh medium and incubated them by shaking at the appropriate temperature to obtain mid-log phase bacteria, approx. $2 \mathrm{~h}$ for E. coli and S. typhimurium, $4 \mathrm{~h}$ for S. meliloti and overnight for Bradyrhizobium.

Note:

a. The use of a mid-log phase culture $\left(O D_{600}=0.3-0.5\right)$ is important to obtain reproducible results since some bacterial species may become insensitive or less sensitive to certain peptides at later growth phases.

b. Bradyrhizobium samples are washed 3 times with 1 volume sterile PBT before proceeding to the next step. This washing step allows the peptides to interact more efficiently with the bacterial membrane.

4. Adjust the bacteria to $1 \times 10^{6}$ to $1 \times 10^{7}$ Colony Forming Units (CFU)/ml (OD600 $~ 0.01$ to 0.05 ) in MHB for E. coli and S. typhimurium or PB for S. meliloti and Bradyrhizobium.

5. Prepare $1 \mathrm{ml}$ aliquots of bacterial suspension in Eppendorf tubes.

6. Add the fluorescently-labelled peptide to the bacteria and incubate samples for chosen times (usually a few minutes to one hour, depending on the bacterial strain and the peptide) at $37^{\circ} \mathrm{C}$ or $30^{\circ} \mathrm{C}$ according to the bacterial strain used. Prepare one tube for each peptide concentration and time point and arrange a negative control without peptide.

Note: To evaluate correctly peptide internalization, select a concentration that is below the membrane-permeabilizing concentration of the peptide. This information can be obtained by a Pl-uptake assay as described in the supplementary Procedure $C$ or Procedure $D$. 
7. Wash samples three times in BHSS (for E. coli and S. typhimurium) or PB (for S. meliloti and Bradyrhizobium) in order to remove the fraction of peptide that is bound weakly to the bacterial surface. Resuspend cells in $1 \mathrm{ml}$ of BHSS or PB, respectively.

8. Analyze samples by the flow cytometer. Gate on the bacterial population using the forward scatter (FSC) and side scatter (SSC) parameters. Use filter settings that are adapted for the fluorophore used. The detector is set to logarithmic amplification. A total number of 10,000 to 50,000 events are usually acquired for each sample.

9. Plot the number of counted events as a function of the fluorescence intensity (Figure 1). Cytometric data analysis may be performed using the FCS Express software, the Summit 6.2.2 software or equivalent software.

10. Add trypan blue to each bacterial sample at $1 \mathrm{mg} / \mathrm{ml}$ final concentration.

11. Incubate 10 min at room temperature and then analyze all samples again as in steps A8 and A9.

B. Confocal scanning laser microscopy

This procedure is complementary to Procedure A. It can confirm for a smaller number of cells peptide uptake or membrane association.

1. Prepare samples as described until step $A 7$ in Procedure $A$.

2. Place 1 to $10 \mu \mathrm{l}$ of each treated bacterial suspension between slide and cover-glass to obtain an immobile monolayer of cells.

3. Observe samples with a confocal laser scanning microscope using a $63 x$ or $100 x$ objective.

4. Analyse the image stacks collected by the confocal microscope using appropriate software, e.g., for image acquisition Leica Application Suite X or EZ-C1 Free Viewer and for image processing ImageJ.

5. Observe the distribution of fluorescence on the cell surface and inside the bacterial cells (Figure 2).

Supplementary procedures: if the membrane permeabilization activity of the peptide of interest is unknown, Procedures $C$ and $D$ can be used to determine a concentration at which the fluorescent peptide does not affect the bacterial membrane permeability, providing a working concentration to be used in Procedures $A$ and $B$.

C. Propidium iodide uptake assay by microplate reader

1. Prepare samples as described until step A3 in Procedure A.

2. Adjust the bacteria to $1 \times 10^{7}$ to $1 \times 10^{8} \mathrm{CFU} / \mathrm{ml}\left(\mathrm{OD}_{600} \sim 0.1\right)$ in $\mathrm{MHB}$ for E. coli and $\mathrm{S}$. typhimurium or PB for S. meliloti and Bradyrhizobium.

3. Add PI to each bacterial sample at $10 \mu \mathrm{g} / \mathrm{ml}$ final concentration.

4. Add samples to a microplate, $190 \mu \mathrm{l}$ per well.

5. Add $10 \mu \mathrm{l}$ peptide to each sample at the required final concentration. 
Note: A range of concentrations should be tested from one tenth of the Minimal Inhibitory Concentration or lower till the minimal inhibitory concentration. Typical Minimal Inhibitory Concentrations for antimicrobial peptides are in the range of 1 to $10 \mu \mathrm{M}$.

6. Immediately measure fluorescence in the fluorescence plate reader. Using Magellan software, acquire data every 2 min for 120 cycles. Filters for PI fluorescence are: excitation 536-539 nm filter; emission 617-620 nm filter.

7. Analyse data in an Excel data sheet (Figure 3).

D. Propidium iodide uptake assay by flow cytometry (alternative to Procedure C)

1. Prepare samples as described until step A4 in Procedure A.

2. Aliquot $1 \mathrm{ml}$ of bacterial suspension into the tubes. Prepare one tube for each concentration of peptide.

3. Add PI to each sample (final concentration $10 \mu \mathrm{g} / \mathrm{ml}$ ).

4. Add the peptide to the desired concentration and incubate in a thermostatic bath at $37^{\circ} \mathrm{C}$.

5. Acquire each sample with the flow cytometer every $15 \mathrm{~min}$ (for maximum $2 \mathrm{~h}$ ).

6. Plot the number of cells as a function of the PI fluorescence signal (at $620 \mathrm{~nm}$ ).

7. For each incubation time, evaluate the percentage of permeabilised cells (Figure 4).

\section{Data analysis}

The flow cytometry analysis will reveal fluorescence positive and negative bacterial populations after treatment with a labelled peptide (Figure 1). Fluorescence negative bacteria can be recognized by comparison with an untreated sample which will help to determine the background signal. Uptake of peptide can be concluded by comparing the Mean Fluorescence Intensity (MFI) values obtained in the absence and in the presence of trypan blue of each sample (Figure 1). Trypan blue is a fluorescence quencher which absorbs light in the range of FITC or BODIPY-FL. Because trypan blue does not penetrate bacterial cells and quenching requires contact between the fluorochrome and the quencher, it will only quench the light emitted by peptides located outside the bacterial cell while light emitted by internalized fluorochrome will be detected. Thus, little or no difference between the MFI values of cells treated with or without trypan blue indicates that the peptide is mainly internalized into bacterial cells; conversely, a large difference between the MFI values indicates that the peptide is mainly located on the bacterial surface or in both the cytoplasm and membranes. In this case, further studies are required to precisely establish the peptide distribution in the cells. For example, bacterial samples treated with fluorescent peptides can be visualized by confocal laser scanning microscopy, without any fixation, and by following the same protocol used for the flow cytometric assay (Figure 2; see Procedure B).

Uptake of an AMP of interest is meaningful, suggesting an intracellular mode of action of the peptide, if it is taking place at a concentration at which the membrane permeability of the target bacteria is not affected by the peptide. Membrane integrity can be determined with PI-uptake assays 
(Procedure C or Procedure D). Dilution series of the peptide of interest will determine the maximum concentration of the peptide at which no PI uptake is observed (same fluorescence level in the AMPtreated sample and the untreated control; Figures 3 and 4). This AMP concentration is a usable concentration for the flow cytometry uptake experiments.

\section{Representative data}

1. A representative example of a flow cytometry experiment demonstrating the uptake of the Bac7 peptide, labelled with BODIPY FL, by S. meliloti wild type and the inability of a mutant in the bacA transporter gene to take up the peptide.
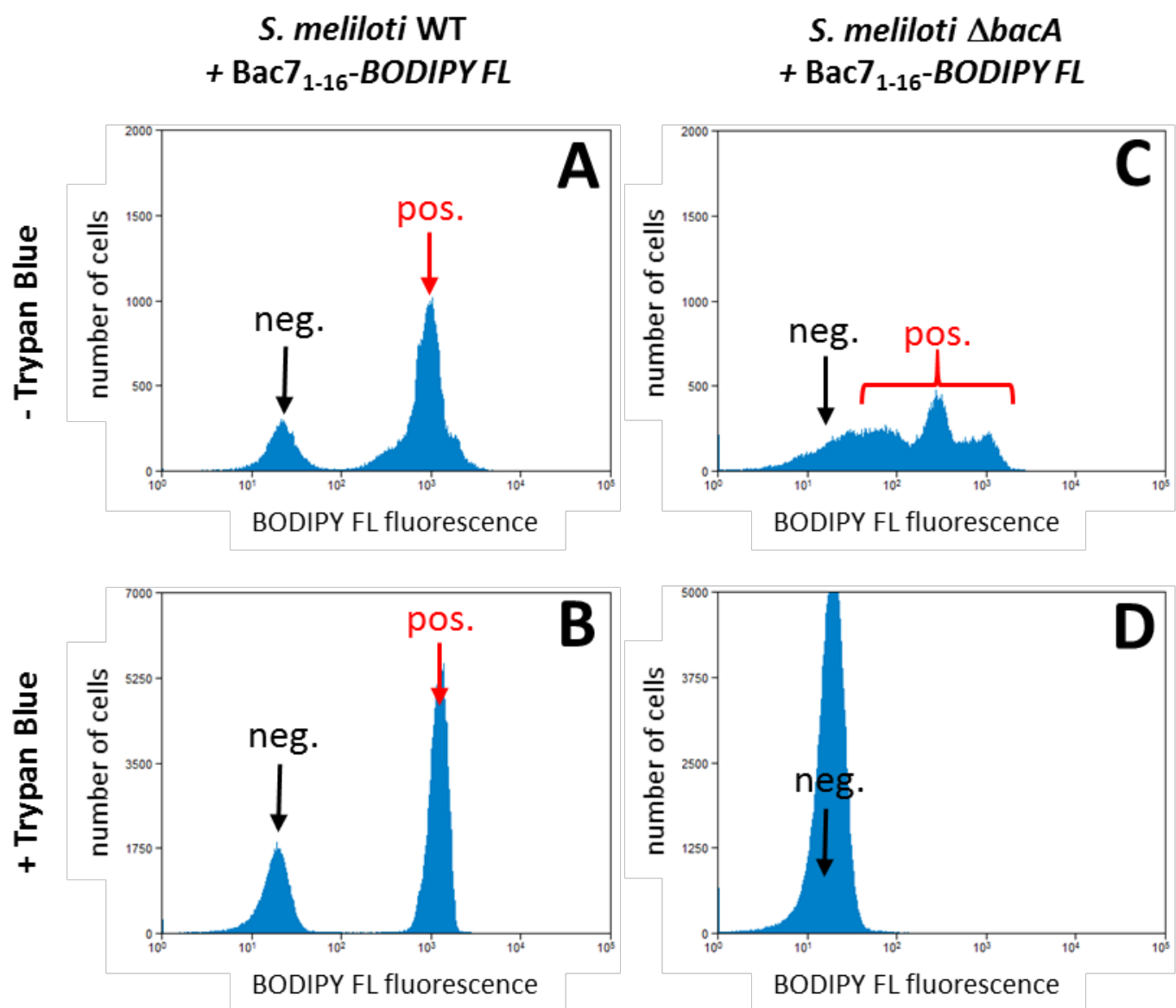

Figure 1. Bac71-16-BODYPI FL uptake by S. meliloti and its bacA mutant. A. The example shows that in the wild type strain, a bacterial population has high fluorescence (red arrow) which is almost 100 times higher than the negative population (bacteria that did not take up the peptide; black arrow). B. The MFI of this positive population (red arrow) is conserved in the presence of trypan blue demonstrating the uptake of the peptide by the bacteria. C. The S. meliloti $\triangle b a c A$ mutant on the other hand shows only a high fluorescence signal in the absence of extracellular fluorescence quencher (red bracket). D. This fluorescence is completely quenched by the presence of trypan blue, demonstrating that this mutant cannot take up the peptide. This 
observation is in agreement with the bacA gene of S. meliloti encoding a transporter required for the uptake of the Bac7 peptide (Marlow et al., 2009). Note that the fluorescence levels in the $\mathrm{x}$-axes are in logarithmic scale.

2. Microscopy analysis shows the intracellular localization of the Bac71-16-BODYPI FL peptide.
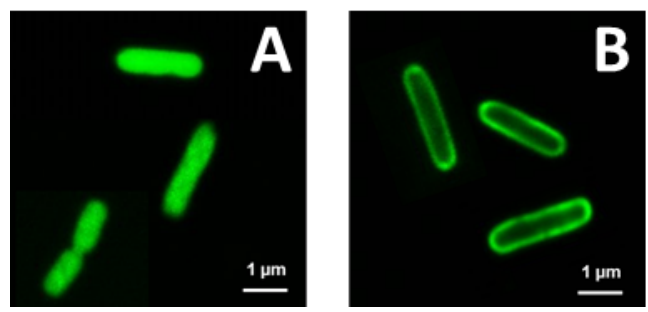

Figure 2. Localization of Bac71-16-BODYPI FL and Polymyxin B-BODYPI FL on E. coli cells observed by CSLM. A. Intracellular accumulation of the Bac71-16-BODYPI FL peptide in the cytosol of the bacterial cells. B. Accumulation on the bacterial surface of the Polymyxin BBODYPI FL, a peptide that target the bacterial envelope.

3. Typical example of a PI-uptake assay demonstrating membrane permeabilization provoked by the AMP NCR247 and measured using a fluorescence plate reader.

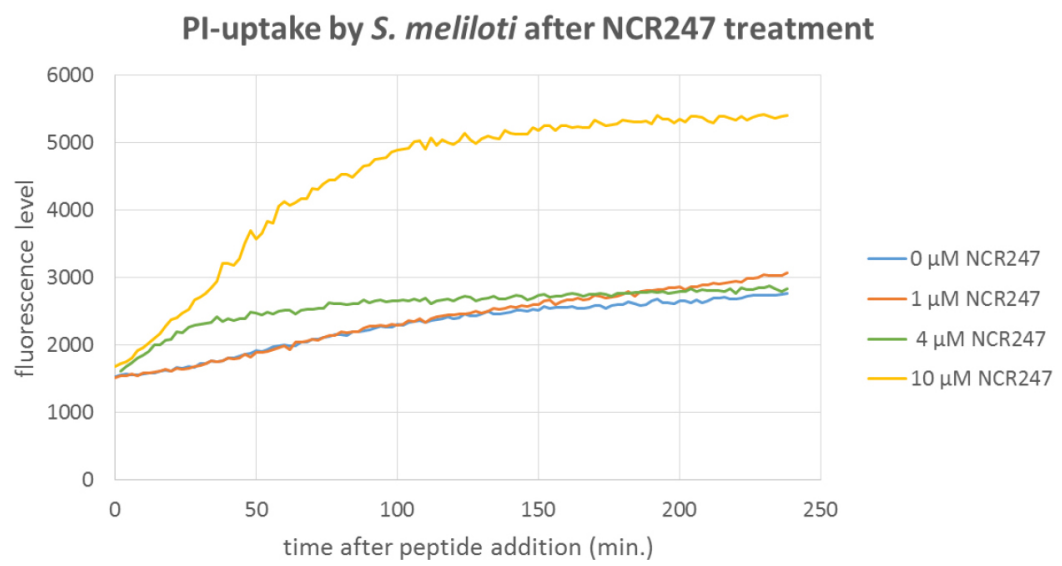

Figure 3. PI-uptake assay with S. meliloti wild type cells treated with the NCR247 AMP. The bacteria were treated with the indicated concentrations of the peptide. At $4 \mu \mathrm{M}$ and particularly at $10 \mu \mathrm{M} \mathrm{PI}$ uptake is observed but not at $1 \mu \mathrm{M}$. Thus the latter concentration is a usable working concentration for peptide uptake assays with Procedure A or B.

4. Determination of the non-lytic condition for a peptide by cytometric PI-uptake assay. 


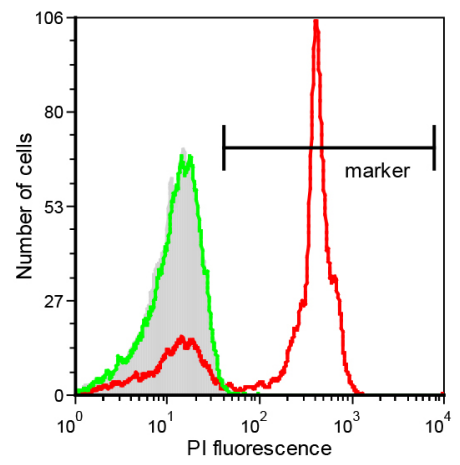

Figure 4. PI-uptake in E. coli cells after treatment with Bac7 $1-16$ and polymyxin B. A marker window is set on the basis of the untreated cell population (grey histograms) to indicate the interval of fluorescence intensity at which the cells are considered PI-positive. The example shows that fluorescence of $E$. coli cells treated with $0.25 \mu \mathrm{M}$ polymyxin B for 10 min shifts to higher values (red histogram), indicating that membranes have been permeabilized. Conversely, fluorescence signal of bacteria incubated with $1 \mu \mathrm{M}$ Bac71-16 for 30 min (green histogram) is superimposed to that of the negative control indicating a non-lytic activity for this peptide at these conditions.

\section{$\underline{\text { Notes }}$}

The fraction of a bacterial population that is responsive and has taken up a fluorescently labelled AMP (relative fraction of positive and negative cells as in Figure 1) may vary between experiments and is depending on the studied bacterial strain and on the identity of the peptide.

\section{$\underline{\text { Recipes }}$}

1. Mueller-Hinton broth (MHB)

$21 \mathrm{~g}$ of dehydrated medium (DIFCO) dissolved in $1 \mathrm{~L}$ of MilliQ water

Autoclave and store at room temperature

For agar plates, add 1.5\% agar before autoclaving

2. Yeast extract broth (YEB, for $1 \mathrm{~L}$ medium)

$5 \mathrm{~g}$ Bacto beef extract

$1 \mathrm{~g}$ Bacto yeast extract

$5 \mathrm{~g}$ Bacto peptone

$5 \mathrm{~g}$ saccharose

$500 \mathrm{mg} \mathrm{MgSO} \cdot 7 \mathrm{H}_{2} \mathrm{O}$

Dissolve in $900 \mathrm{ml}$ MilliQ water

Adjust the pH to 7.2 with $1 \mathrm{~N} \mathrm{NaOH}$, adjust the volume to $1 \mathrm{~L}$, autoclave and store at room temperature

For agar plates, add 1.5\% agar before autoclaving 
3. Yeast extract mannitol broth (YMB, for $1 \mathrm{~L}$ medium)

$10 \mathrm{~g}$ mannitol

$500 \mathrm{mg} \mathrm{K}_{2} \mathrm{HPO}_{4}$

$500 \mathrm{mg}$ sodium glutamate

$1 \mathrm{~g}$ yeast extract

$50 \mathrm{mg} \mathrm{NaCl}$

$40 \mathrm{mg} \mathrm{CaCl} \cdot 2 \mathrm{H}_{2} \mathrm{O}$

$4 \mathrm{mg} \mathrm{FeCl} 3$

$100 \mathrm{mg} \mathrm{MgSO} \cdot 7 \mathrm{H}_{2} \mathrm{O}$

Dissolve in $900 \mathrm{ml}$ MilliQ water

Adjust the $\mathrm{pH}$ to 6.8 with $1 \mathrm{~N} \mathrm{HCl}$, adjust the volume to $1 \mathrm{~L}$, autoclave and store at room temperature

For agar plates, add 1.5\% agar before autoclaving

4. Buffered-saline (BS)

$10 \mathrm{mM}$ Na-phosphate buffer containing $150 \mathrm{mM} \mathrm{NaCl}, \mathrm{pH} 7.4$

Filtered using a $0.2 \mu \mathrm{m}$ membrane filter

5. Buffered high salt solution (BHSS)

$10 \mathrm{mM}$ Na-phosphate

$400 \mathrm{mM} \mathrm{NaCl}$

$10 \mathrm{mM} \mathrm{MgCl} 2$

Adjust the $\mathrm{pH}$ to 7.4

Filtered using a $0.2 \mu \mathrm{m}$ membrane filter

6. Phosphate buffer (PB)

$50 \mathrm{mM}$ Na-phosphate

Adjust the $\mathrm{pH}$ to 7.0

Filtered using a $0.2 \mu \mathrm{m}$ membrane filter

7. PB supplemented with Tween 20 (PBT)

$50 \mathrm{mM}$ Na-phosphate

0.05\% (vol/vol) Tween 20

Adjust the $\mathrm{pH}$ to 7.0

Filtered using a $0.2 \mu \mathrm{m}$ membrane filter

8. Trypan blue stock solution

$10 \mathrm{mg} / \mathrm{ml}$ trypan blue in BS solution

Filtered using a $0.2 \mu \mathrm{m}$ membrane filter

9. Propidium iodide $(\mathrm{PI})$ stock solution

$1 \mathrm{mg} / \mathrm{ml}$ in MilliQ water or BS solution

Filtered using a $0.2 \mu \mathrm{m}$ membrane filter 


\section{Acknowledgments}

The present work has benefited from the core facilities of Imagerie-Gif, (http://www.i2bc.parissaclay.fr), member of IBiSA (http://www.ibisa.net), supported by 'France-Biolmaging' (ANR-10INBS-04-01), and the Labex 'Saclay Plant Science' (ANR-11-IDEX-0003-02). This work was funded by grant ANR-13-BSV7-0013 and by the University of Trieste grant FRA2014.

\section{References}

1. Arnold, M. F. F., Haag, A. F., Capewell, S., Boshoff, H. I., James, E. K., McDonald, R., Mair, I., Mitchell, A. M., Kerscher, B., Mitchell, T. J., Mergaert, P., Barry 3rd, C. E. Scocchi, M., Zanda, M., Campopiano D. J. and Ferguson, G.P. (2013). Partial complementation of Sinorhizobium meliloti bacA mutant phenotypes by the Mycobacterium tuberculosis BacA protein. $J$ Bacteriol 195(2): 389-398.

2. Benincasa, M., Pacor, S., Gennaro, R. and Scocchi, M. (2009). Rapid and reliable detection of antimicrobial peptide penetration into Gram-negative bacteria based on fluorescence quenching. Antimicrob Agents Chemother 53(8): 3501-3504.

3. Benincasa, M., Pelillo, C., Zorzet, S., Garrovo, C., Biffi, S., Gennaro, R. and Scocchi, M. (2010). The proline-rich peptide Bac7(1-35) reduces mortality from Salmonella typhimurium in a mouse model of infection. BMC Microbiol 10: 178.

4. Benincasa, M., Zahariev, S., Pelillo, C., Milan, A., Gennaro, R. and Scocchi, M. (2015). PEGylation of the peptide Bac7(1-35) reduces renal clearance while retaining antibacterial activity and bacterial cell penetration capacity. Eur J Med Chem 95: 210-219.

5. Farkas, A., Maroti, G., Durgo, H., Gyorgypal, Z., Lima, R. M., Medzihradszky, K. F., Kereszt, A., Mergaert, P. and Kondorosi, E. (2014). Medicago truncatula symbiotic peptide NCR247 contributes to bacteroid differentiation through multiple mechanisms. Proc Natl Acad Sci U S A 111(14): 5183-5188.

6. Guefrachi, I., Pierre, O., Bourge, M., Timchenko, T., Alunni, B., Czernic, P., Villaécija-Aguilar, J.A., Verly, C., Fardoux, J., Mars, M., Kondorosi, E., Giraud, E. and Mergaert, P. (2015). Bradyrhizobium BClA is a NCR peptide transporter required for bacterial differentiation in symbiosis with Aeschynomene. Mol Plant-Microbe Interact 28(11): 1155-1166.

7. Guida, F., Benincasa, M., Zahariev, S., Scocchi, M., Berti, F., Gennaro, R. and Tossi, A. (2015). Effect of size and N-terminal residue characteristics on bacterial cell penetration and antibacterial activity of the proline-rich peptide Bac7. J Med Chem 58(3): 1195-1204.

8. Kondorosi, E., Mergaert, P. and Kereszt, A. (2013). A paradigm for endosymbiotic life: Cell differentiation of Rhizobium bacteria provoked by host plant factors. Annu Rev Microbiol 67: 611-628. 
9. Mardirossian, M., Grzela, R., Giglione, C., Meinnel, T., Gennaro, R., Mergaert, P. and Scocchi, M. (2014). The host antimicrobial peptide Bac71-35 binds to bacterial ribosomal proteins and inhibits protein synthesis. Chem Biol 21(12): 1639-1647.

10. Marlow, V. L., Haag, A. F., Kobayashi, H., Fletcher, V., Scocchi, M., Walker, G. C. and Ferguson, G. P. (2009). Essential role for the BacA protein in the uptake of a truncated eukaryotic peptide in Sinorhizobium meliloti.J Bacteriol 191(5): 1519-1527.

11. Maróti, G., Kereszt, A., Kondorosi, E. and Mergaert, P. (2011). Natural roles of antimicrobial peptides in microbes, plants and animals. Res Microbiol 162(4): 363-374.

12. Mattiuzzo, M., Bandiera, A., Gennaro, R., Benincasa, M., Pacor, S., Antcheva, N. and Scocchi, M. (2007). Role of the Escherichia coli SbmA in the antimicrobial activity of proline-rich peptides. Mol Microbiol 66(1): 151-163.

13. Runti, G., del Carmen Lopez Ruiz, M., Stoilova, T., Hussain, R., Jennions, M., Choudhury, H. G., Benincasa, M., Gennaro, R., Beis, K. and Scocchi, M. (2013). Functional characterization of SbmA, a bacterial inner membrane transporter required for importing the antimicrobial peptide Bac7(1-35). J Bacteriol 195(23): 5343-5351.

14. Scocchi, M., Mardirossian, M., Runti, G. and Benincasa, M. (2016). Non-membrane permeabilizing modes of action of antimicrobial peptides on bacteria. Curr Top Med Chem 16(1): 76-88.

15. Wang, G., Mishra, B., Lau, K., Lushnikova, T., Golla, R. and Wang, X. (2015). Antimicrobial peptides in 2014. Pharmaceuticals (Basel) 8(1): 123-150. 